\title{
Authors' reply: Application of Bayesian methods to the inference of phylogeny for enterovirus surveillance
}

M Koopmans (marion.koopmans@rivm.nl)1,2, H G Niesters³, K Benschop ${ }^{1,4}$, K Wolthers ${ }^{4}$, R Schuurman ${ }^{5}$, S D Pas ${ }^{2}$, E C Claas ${ }^{6}$,

A Kroneman $^{1}$, J C Rahamat-Langendoen ${ }^{3}$, H Vennema ${ }^{3}$, H van der Avoort ${ }^{1}$

1. Laboratory for Infectious Diseases and Screening, Center for Infectious Diseases, National Institute of Public Health and the Environment (RIVM), Bilthoven, the Netherlands

2. Department of Virology, Erasmus Medical Centre, Rotterdam, the Netherlands

3. Department of Medical Microbiology, Division of Clinical Virology, University of Groningen, University Medical Center Groningen, the Netherlands

4. Department of Medical Microbiology, Academic Medical Center, Amsterdam, the Netherlands

5. Department of Medical Microbiology, University Medical Center Utrecht, Utrecht, the Netherlands

6. Department of Medical Microbiology, Leiden University Medical Centre, Leiden, the Netherlands

Citation style for this article:

Koopmans M, Niesters HG, Benschop K, Wolthers K, Schuurman R, Pas SD, Claas EC, Kroneman A, Rahamat-Langendoen JC, Vennema H, van der Avoort H. Authors' reply: Application of Bayesian methods to the inference of phylogeny for enterovirus surveillance. Euro Surveill. 2013;18(9):pii=20410. Available online: http://

www.eurosurveillance.org/ViewArticle.aspx?Articleld=20410

Article submitted on 25 February 2013 / published on 28 February 2013

\section{To the editor:}

We would like to thank Roberts et al. for their comments on our paper entitled 'Laboratory-based surveillance in the molecular era: the TYPENED model, a joint data-sharing platform for clinical and public health laboratories' [1]. We fully agree with the remarks on the potential strength of adding more advanced analytical tools once the molecular surveillance network is established. In fact, this is what we have done previously, as part of studies of the evolution of noroviruses and enteroviruses $[2,3]$. For enteroviruses, we focused those studies on enterovirus $71\left(E_{71}\right)$, for the reasons mentioned by Roberts et al. We compared the evolutionary trajectory of EV71 in the Netherlands with that from a systematic collection of EV 71 strains detected in southern China. This analysis showed a clear difference in the circulating strains, with evidence that the EV71 subgenogroups B and C circulating in Asia have evolved further than those in Europe and the United States [3,4]. The severity of outbreaks of EV71 infection associated with the EV 71 lineages circulating in Asia raises the question if these viruses need to be regarded as an emerging public health problem [5]. The analysis also showed that previous peaks in reporting reflected true epidemics [3]. Further studies showed that recombination was part of the driving force for those epidemics [6]. We agree that such studies give a much deeper understanding of the epidemiology of enteroviruses, and would strongly support its development in an international context. The rapid transition from culture-based diagnostic methods to molecular diagnostics in clinical virology in our country was a trigger to do this, and will most likely also affect other surveillance systems such as those for influenza or food-borne bacterial pathogens [7]. However, at present, this transition has not been made in most countries globally. Our article aimed to describe the model applied in the Netherlands for an approach to molecular surveillance, in which clinical and public health laboratories collaborate by defining common goals. This model was developed to facilitate the transition, and includes comparative evaluation of surveillance trends obtained by classical and molecular virological methods 1 . If outcomes are agreed upon, we will further develop the system, which would include the more advanced analytical approaches suggested by Roberts et al.

\section{Conflict of interest}

None declared.

\section{Authors' contributions}

Marion Koopmans drafted the response letter after discussions and input from the authors of the article in question.

\section{References}

1. Niesters HG, Rossen JW, van der Avoort H, Baas D, Benschop $\mathrm{K}$, Claas EC, et al. Laboratory-based surveillance in the molecular era: the TYPENED model, a joint data-sharing platform for clinical and public health laboratories. Euro Surveill. 2013;18(4):pii=20387. Available from: http://www. eurosurveillance.org/ViewArticle.aspx?Articleld=20387

2. Siebenga JJ, Lemey P, Kosakovsky Pond SL, Rambaut A, Vennema H, Koopmans M. Phylodynamic reconstruction reveals norovirus GII.4 epidemic expansions and their molecular determinants. PLoS Pathog. 2010;6(5):e1000884.

3. van der Sanden S, van der Avoort H, Lemey P, Uslu G, Koopmans M. Evolutionary trajectory of the VP1 gene of human enterovirus 71 genogroup B and C viruses. J Gen Virol. 2010;91(Pt 8):1949-58.

4. Guan D, van der Sanden S, Zeng H, Li W, Zheng H, Ma C, et al. Population dynamics and genetic diversity of $\mathrm{C}_{4}$ strains of human enterovirus 71 in Mainland China, 1998-2010. PLoS One. 2012;7(9):e44386.

5. Solomon T, Lewthwaite P, Perera D, Cardosa MJ, McMinn P, Ooi MH. Virology, epidemiology, pathogenesis, and control of enterovirus 71. Lancet Infect Dis. 2010;10(11):778-90. http:// dx.doi.org/10.1016/S1473-3099(10)70194-8 
6. van der Sanden S, van Eek J, Martin DP, van der Avoort $\mathrm{H}$, Vennema H, Koopmans M. Detection of recombination breakpoints in the genomes of human enterovirus 71 strains isolated in the Netherlands in epidemic and non-epidemic years, 1963-2010. Infect Genet Evol. 2011;11(5):886-94.

http://dx.doi.org/10.1016/j.meegid.2011.02.011

PMid:21352955

7. Jones TF, Gerner-Smidt P. Nonculture diagnostic tests

for enteric diseases. Emerg Infect Dis. 2012;18(3):513-4.

http://dx.doi.org/10.3201/eid1803.111914 PMid:22377326 PMCid:3309642 